\title{
BMJ Open Nipple sparing versus skin sparing mastectomy: a systematic review protocol
}

\author{
Riaz A Agha, ${ }^{1}$ Georgina Wellstead, ${ }^{2}$ Harkiran Sagoo, ${ }^{3}$ Yasser Al Omran, ${ }^{2}$ \\ Ishani Barai, ${ }^{4}$ Shivanchan Rajmohan, ${ }^{4}$ Alexander J Fowler, ${ }^{5}$ Dennis P Orgill, ${ }^{6}$ \\ Jennifer E Rusby ${ }^{7}$
}

To cite: Agha RA, Wellstead G, Sagoo $\mathrm{H}$, et al. Nipple sparing versus skin sparing mastectomy: a systematic review protocol. BMJ Open 2016;6:e010151. doi:10.1136/bmjopen-2015010151

- Prepublication history for this paper is available online. To view these files please visit the journal online (http://dx.doi.org/10.1136/ bmjopen-2015-010151).

Received 3 October 2015 Revised 8 March 2016 Accepted 10 March 2016

CrossMark

For numbered affiliations see end of article.

Correspondence to Dr Alexander J Fowler; alexjfowler@gmail.com

\section{ABSTRACT}

Introduction: Breast cancer has a lifetime incidence of one in eight women. Over the past three decades there has been a move towards breast conservation and a focus on aesthetic outcomes while maintaining oncological safety. For some patients, mastectomy is the preferred option. There is growing interest in the potential use of nipple sparing mastectomy (NSM). However, oncological safety remains unproven, and the benefits and indications have not been clearly identified. The objective of this systematic review will be to determine the safety and efficacy of NSM as compared with skin sparing mastectomy (SSM).

Methods and analysis: All original comparative studies including; randomised controlled trials, cohort studies and case-control studies involving women undergoing either NSM or SSM for breast cancer will be included. Outcomes are primary-relating to oncological outcomes and secondary-relating to clinical, aesthetic, patient reported and quality of life outcomes. A comprehensive electronic literature search, designed by a search specialist, will be undertaken. Grey literature searches will also be conducted. Eligibility assessment will occur in two stages; title and abstract screening and then full text assessment. Each step will be conducted by two trained teams acting

independently. Data will then be extracted and stored in a database with standardised extraction fields to facilitate easy and consistent data entry. Data analysis will be undertaken to explore the relationship between NSM or SSM and preselected outcomes, heterogeneity will be assessed using the Cochrane tests.

Ethics and dissemination: This systematic review requires no ethical approval. It will be published in a peer-reviewed journal. It will also be presented at national and international conferences. Updates of the review will be conducted to inform and guide healthcare practice and policy.

\section{BACKGROUND}

Breast cancer epidemiology

Breast cancer is the most common cancer in the UK and accounts for $31 \%$ of all new
Strengths and limitations of this study

- Multidisciplinary team conducting a noncommercial systematic review and meta-analysis in an important topic.

- Team has specific experience and training in conducting meta-analysis and systematic review.

- Potential lack of high quality studies limiting the ability to conduct robust meta-analysis.

- Potential reporting bias within the existing literature.

cancer cases, with a lifetime incidence of 1 in 8 in women. ${ }^{1}$ Fifty thousand women are diagnosed with breast cancer each year, 16000 of whom undergo mastectomy. There are also approximately 12000 deaths from the disease. ${ }^{2}$ Similarly, in the USA, the National Cancer Institute predicted 232340 new cases and 39620 deaths from breast cancer in 2013 with over 96000 undergoing breast reconstruction following surgery. ${ }^{3}$

\section{The history of mastectomy}

Halsted's radical mastectomy had been the standard of care for patients since its inception in 1894 up to the 1960s. Patey described the modified radical mastectomy, which achieved a local recurrence rate of $10 \%$ after 10 years. ${ }^{4}$ Skin sparing mastectomy (SSM) was first described in 1991 by Toth and Lappert; it involves removing the entire breast and nipple-areola complex (NAC) while maintaining the skin envelope and the native inframammary fold (IMF) ${ }^{5}$ A subsequent meta-analysis by Lanitis et at in 2010 found that local recurrence rates after SSM are equivalent to those after modified radical mastectomy (MRM).

The advent of nipple sparing mastectomy What are the pros and cons of nipple preservation? The fundamental reason for 
attempting nipple preservation is aesthetics, with studies reporting psychological benefits and improved patient satisfaction. ${ }^{7}$ The nipple is one of the key defining visual features of a breast. With removal of the NAC, the point in the profile at which the most natural convexity occurs is lost. ${ }^{8}$ Preserving the NAC also eliminates the need for staged nipple reconstruction and areola tattooing, after which there can be loss of projection and fading over time, respectively.

Traditionally mastectomy has included resection of the NAC together with the gland. The concern being that the NAC may harbour occult tumour cells. Indeed, large trials have shown the NAC to be involved in $5-12 \%$ of cases. The earliest report of nipple sparing mastectomy (NSM) came from Hinton in 1984, who reported that NSM achieved comparable local recurrence rates and survival to that of MRM. ${ }^{9}$ However, the technique did not achieve widespread use due to oncological concerns at the time, and these concerns persist still. ${ }^{10}{ }^{11}$ Previously, NSM was approached cautiously in the context of patients who had received neoadjuvant chemotherapy, but recent data suggest this may be safe. ${ }^{12}$ Similar concerns were raised over the oncological safety of breast conserving surgery for small tumours until Veronesi et al published their seminal randomised controlled trial (RCT) with 20-year follow-up showing equivalent oncological outcomes to mastectomy. ${ }^{12}$ The treatment of breast cancer has become more nuanced over the past few decades, and a gradual process of systematic improvement has taken place to improve outcomes, both oncologically and aesthetically. ${ }^{14}$ Treatments are tailored to individuals and care is directed through multidisciplinary teams. So does therapeutic NSM have an oncologically safe role in carefully selected patients?

\section{What have we learnt from prior systematic reviews?}

Table 1 below summarises recent systematic reviews assessing NSM.

The quality of the previous systematic reviews is assessed in table 2 below using the validated assessment tool 'Assessment of Multiple Systematic Reviews' (AMSTAR). ${ }^{16-18}$

Why is it important to do this systematic review?

NSM is an active research front. A basic search using the database Scopus for 'nipple sparing mastectomy' reveals how research and interest in this area has increased in recent years (figure 1):

Table 1 Prior reviews of nipple sparing mastectomy

\begin{tabular}{lll}
\hline Review & $\begin{array}{l}\text { Databases included and } \\
\text { years searched }\end{array}$ & $\begin{array}{l}\text { Studies/patients } \\
\text { included }\end{array}$ \\
\hline Zhang et al & PubMed, 1978-2014 & $\begin{array}{l}\text { 27 studies, 7971 } \\
\text { patients }\end{array}$ \\
$2015^{18}$ & & .
\end{tabular}

\section{Key findings}

'Owing to the statistical heterogeneity detected with certain parameters, further investigations to confirm their association with nipple involvement [NI] will be needed. Patients with one or more risk factors such as centrally located tumours; higher tumour stage; large tumours; ER negative/PR negative/HER positive status and associated DCIS have higher risk of NI.

Taking these factors into consideration comprehensively may help with decision-making process for NSM.'

'Review of oncological outcomes in the 10 studies (representing 1148 mastectomies) with documented mean/median follow-up of 2 years demonstrated an overall locoregional recurrence rate of $2.8 \%$.

Ischaemic complications involving the NAC were reported in 24 studies (representing 3091 mastectomies), with $9.1 \%$ of cases reported to have some degree of NAC necrosis and $2.0 \%$ of cases complicated by complete necrosis leading to NAC loss. Sixteen studies (representing 2213 mastectomies) reported rates of skin flap necrosis, which occurred in $9.5 \%$ of cases.'

'Nipple sparing mastectomy appears to be an oncologically safe option for properly selected patients, with low rates of locoregional and distant metastasis. Overall complication and nipple necrosis rates are affected by incision location and reconstruction method.' Adverse oncological outcomes of NSM in carefully selected women with early stage breast cancer were not detected. 
Table 2 Quality of prior systematic review according to AMSTAR

\begin{tabular}{|c|c|c|c|c|}
\hline AMSTAR Criterion & $\begin{array}{l}\text { Zhang et al } \\
2015^{18}\end{array}$ & $\begin{array}{l}\text { Piper et al } \\
2013^{19}\end{array}$ & $\begin{array}{l}\text { Endara et al } \\
2013^{20}\end{array}$ & $\begin{array}{l}\text { De La Cruz } \\
\text { et al } 2015^{21}\end{array}$ \\
\hline 1. Was an 'a priori' design provided? & NO & NO & NO & NO \\
\hline $\begin{array}{l}\text { 2. Was there duplicate study selection and data } \\
\text { extraction? }\end{array}$ & $\begin{array}{l}\text { NO (only data } \\
\text { extraction) }\end{array}$ & NO & YES & YES \\
\hline $\begin{array}{l}\text { 3. Was a comprehensive literature search } \\
\text { performed? }\end{array}$ & $\begin{array}{l}\text { NO (single } \\
\text { database only) }\end{array}$ & $\begin{array}{l}\text { NO (only two } \\
\text { databases) }\end{array}$ & $\begin{array}{l}\text { NO (only two } \\
\text { databases) }\end{array}$ & YES \\
\hline $\begin{array}{l}\text { 4. Was the status of publication (i.e, grey } \\
\text { literature) used as an inclusion criterion? }\end{array}$ & NO & NO & NO & NO \\
\hline $\begin{array}{l}\text { 5. Was a list of studies (included and excluded) } \\
\text { provided? }\end{array}$ & $\begin{array}{l}\text { NO } \\
\text { (included only) }\end{array}$ & $\begin{array}{l}\text { NO } \\
\text { (included only) }\end{array}$ & NO & NO \\
\hline $\begin{array}{l}\text { 6. Were the characteristics of the included studies } \\
\text { provided? }\end{array}$ & YES & YES & YES & YES \\
\hline $\begin{array}{l}\text { 7. Was the scientific quality of the included } \\
\text { studies assessed and documented? }\end{array}$ & NO & NO & YES & NO \\
\hline $\begin{array}{l}\text { 8. Was the scientific quality of the included } \\
\text { studies used appropriately in formulating } \\
\text { conclusions? }\end{array}$ & NO & NO & YES & YES \\
\hline $\begin{array}{l}9 \text { Were the methods used to combine the findings } \\
\text { of studies appropriate? }\end{array}$ & YES & NA & YES & YES \\
\hline $\begin{array}{l}\text { 10. Was the likelihood of publication bias } \\
\text { assessed? }\end{array}$ & YES & NO & NO & NO \\
\hline 11. Was the conflict of interest stated? & YES & YES & YES & YES \\
\hline Total & 4 & 2 & 6 & 6 \\
\hline
\end{tabular}

Since the most recent systematic review of NSM concluded its search in January 2014, there have been over 100 more articles published in this area (figure 1). ${ }^{13} \mathrm{~A}$ new systematic review is needed to update our understanding of this rapidly evolving area and potentially answer the questions previous studies have failed to.

\section{OBJECTIVES}

Our objective is to perform a comprehensive systematic review of NSM with a particular focus on safety and efficacy.

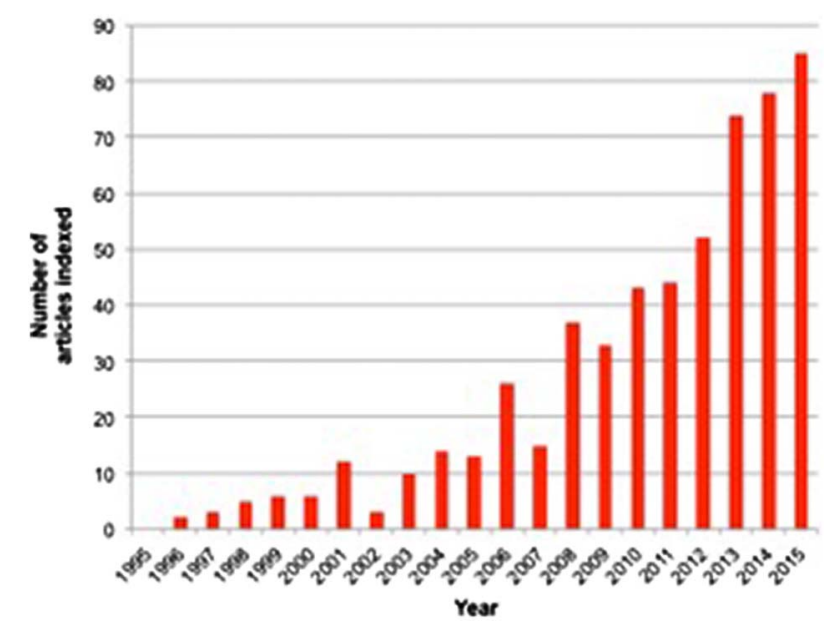

Figure 1 Number of articles published per year and indexed by Scopus under the search term 'nipple sparing mastectomy'.
Primary objectives

In the context of using NSM for women with breast cancer, we aim to determine its:

1. Oncological outcomes

2. Clinical outcomes

3. Aesthetic outcomes

4. Patient reported outcomes

5. Quality of life outcomes

\section{Secondary objectives}

1. To determine the contraindications for the procedure.

2. To help refine patient selection for the procedure.

\section{METHODS}

This review will be conducted in line with the recommendations specified in the Cochrane Handbook for intervention reviews V.5.1.0 and is AMSTAR compliant. ${ }^{22}$ It will be reported in line with the Preferred Reporting Items for Systematic Reviews and Meta-Analyses (PRISMA) statement. ${ }^{23}$ This protocol has been developed a priori and registered on the Research Registry UIN: reviewregistry29 (http://www.researchregistry.com).

\section{Criteria for selecting studies for this review}

The following inclusion and exclusion criteria were explicitly formulated to minimise heterogeneity and address the research questions asked.

\section{Types of studies}

All comparative studies including: RCTs; cohort and case-control studies will be included. Hence, levels of 
evidence $1-3$, as defined by the Oxford Centre for Evidence-Based Medicine with exclusion of single group cohorts, case series, case reports and expert opinion. ${ }^{24}$ Only articles which mention one or more of the outcomes of interest will be included. Duplicate studies will be excluded as will: cost-effectiveness studies and those where original data are not reported, or purely technical descriptions.

\section{Types of participants}

Women undergoing mastectomy for breast cancer. Male and transgender cases will be excluded.

\section{Types of interventions}

NSM, which involves the removal of all glandular breast tissue and preservation of the native skin envelope, IMF and nipple. Subcutaneous mastectomy will be excluded.

\section{Types of comparators}

Where possible, the intervention will be compared with skin sparing mastectomy-where the nipple-areola complex and the gland are removed but the skin and inframammary crease are preserved.

\section{Types of outcome measures}

Primary outcomes include overall survival and local recurrence rate in the follow-up period. Secondary outcomes include: clinical complications such as NAC or skin flap necrosis, haematoma, seroma, infection and readmission to hospital. Also aesthetic outcomes as judged by the relevant instrument used in the study, patient reported outcomes (such as patient satisfaction) and quality of life outcomes such as psychological wellbeing, impact on body image, relationships and sexuality, using instruments like EQ-5D.

\section{Search methods for identification of studies Electronic searches}

The following electronic databases will be searched from inception to 31 December 2015: MEDLINE, EMBASE, SciELO, The Cochrane Library, including the Cochrane Database of Systematic Reviews (CDSR), Cochrane Central Register of Controlled Trials (CENTRAL), Database of Abstracts of Reviews of Effect (DARE), the Cochrane Methodology Register, Health Technology Assessment Database, the NHS Economic Evaluation Databases and Cochrane Groups, ClinicalTrials.gov, the WHO International Clinical Trials Registry Platform.

\section{Search terms and keywords}

A search will be constructed and conducted by an information specialist experienced in systematic review, using appropriate keywords in the English language combined with Boolean logical operators. The search strategy for MEDLINE is shown below as an example (table 3):

Searches will be translated to the appropriate syntax of other databases, free text and the relevant database thesaurus terms will be used.
Table 3 Literature search strategy

\begin{tabular}{|c|c|c|}
\hline \# & Search & Results \\
\hline 1 & exp Breast Neoplasms/su (Surgery) & 31262 \\
\hline 2 & exp Mastectomy/ & 24336 \\
\hline 3 & (breast $^{*}$ adj2 (surg ${ }^{\star}$ or reconstruct $\left.\left.{ }^{\star}\right)\right] . t i, a b$. & 15404 \\
\hline 4 & mastectom*.ti,ab. & 16370 \\
\hline 5 & 1 or 2 or 3 or 4 & 50022 \\
\hline 6 & $\begin{array}{l}{[(\text { nipple* or areola* or nac) adj3 (spare? or }} \\
\left.\left.\text { sparing or preserv }^{\star} \text { or reposition }{ }^{\star}\right)\right] . t i, a b .\end{array}$ & 513 \\
\hline 7 & 5 and 6 & 424 \\
\hline 8 & Nipples/and Organ Sparing Treatment/ & 21 \\
\hline 9 & 7 or 8 & 426 \\
\hline
\end{tabular}

Reports will not be excluded based on their publication status. The search will not be limited by language and non-English full texts will proceed to title and abstract screening (since the abstract will be in English). If the full paper is required authors will be contacted to provide a translated copy. If this is not possible, native language speaker translation will be undertaken. Finally, Google Translate (Google, Mountain View, California, USA) will be used. ${ }^{25}$ It has been recognised as an approach to potentially minimise language bias in systematic reviews. ${ }^{26}$

\section{Searching other resources}

Grey literature searches will include a search of Open Grey (http://www.opengrey.eu). In addition, references of all included papers and prior systematic reviews will be searched for any relevant studies that were not already captured through our search.

\section{Identification and selection of studies}

Studies identified through the electronic and manual searches will be listed within a Microsoft Excel 2011 database and duplicates excluded (Microsoft, Redmond, Washington, USA). The selection of articles will be conducted in two stages by individuals trained in the process and who will be given detailed eligibility instructions:

1. Titles and abstracts will be screened by two researchers. Discrepancies will be resolved through discussion. If any doubt about inclusion exists, the article will proceed to the next stage.

2. The full-text of the articles selected above will be downloaded and further assessed for inclusion by two researchers. Discrepancies will be resolved by consensus. If this is not possible, one of the senior authors will be asked to make a final decision as to inclusion.

Where required, authors will be contacted to clarify inclusion, data overlap and data. Once final decisions on study inclusion have been made, data will be extracted from included studies.

\section{Data extraction, collection and management}

Data extraction will be performed independently by two teams of researchers. Discrepancies will then be resolved by consensus. Final decisions on data will be made by a senior author. 
Data will be extracted into a standardised Microsoft Excel 2011 (Microsoft, Redmond, Washington, USA) database. The following data will be extracted:

- Author names, countries and year of publication

- Study design and level of evidence

- Conflicts of interest and funding

- Number of participants

- Number of breasts treated

- Intention-risk reducing or therapeutic

- Age of participants

- Oncological parameters-type of cancer (invasive or in situ), grade, stage, axillary nodal status, hormone receptor status (ER, PR), HER2 status, size of tumour, tumour-nipple distance, solitary or multifocal or multicentric and presence of lymphovascular invasion.

- Prior adjuvant radiotherapy

- Prior neoadjuvant or adjuvant chemotherapy

- Previous breast surgery

- Technical details-incision used and reconstruction performed

- Median follow-up duration

- Loss to follow-up expressed as a percentage

- Outcomes-primary and secondary as described above

\section{Assessment of risk of bias in included studies}

We will use the Cochrane Risk of Bias Tool for RCTs. ${ }^{27}$ This examines the following domains: sequence generation; allocation concealment; blinding of participants; personnel and outcome assessors; incomplete outcome data; selective outcome reporting and other sources. For Non-Randomised studies we will use the relevant Cochrane Risk of Bias Assessment Tool ACROBAT-NRSI. ${ }^{28}$

We will compare study protocols with final papers where possible. Key missing information across all study types will be presented.

\section{Assessment of publication bias}

We will analyse funnel plot asymmetry to determine if there is a deficiency of reports of negative study outcomes. ${ }^{29}$

\section{Strategy for data synthesis and statistical analysis}

Outcomes of interest will be presented appropriately. When possible, NSM and SSM will be compared. Using Review Manager V.5.2.6 (RevMan), an assessment of heterogeneity in comparative studies will be made (Copenhagen: The Nordic Cochrane Centre, The Cochrane Collaboration. Review Manager (RevMan) Version 5.2. 2012). If high as defined by the $\mathrm{I}^{2}$ statistic $\left(\mathrm{I}^{2}>50 \%\right)$, meta-analysis will be performed using a random effects model, otherwise a fixed effects model will be used. ${ }^{26}$

\section{Subgroup analysis}

We will perform an additional analysis to see if particular oncological profiles are associated with better outcomes post-NSM.

\section{Dissemination}

Based on the results of this systematic review, independent analysis and recommendations will be made to clinicians, researchers, plastic and breast surgical societies and policy makers. Authors of guidelines relating to oncological breast surgery will be informed of the results directly. It will be published in a peer-reviewed journal and presented at national and international conferences. A lay summary and short summary will be disseminated to the appropriate audiences by email.

\section{Author affiliations}

'Department of Plastic Surgery, Guy's and St. Thomas' NHS Foundation Trust, London, UK

'Bart's and The London School of Medicine and Dentistry, Queen Mary and Westfield University, London, UK

${ }^{3}$ GKT School of Medical Education, King's College London, London, UK ${ }^{4}$ Imperial College School of Medicine, London, UK

${ }^{5}$ Department of Medicine, Guy's and St. Thomas' NHS Foundation Trust, London, UK

${ }^{6}$ Division of Plastic Surgery, Brigham and Women's Hospital, Boston, Massachusetts, USA

${ }^{7}$ Breast Unit, The Royal Marsden NHS Foundation Trust, Sutton, UK

Twitter Follow Alexander Fowler at @buzzlogic

Contributors RAA, GW, HS, YAO, IB, SR, AJF, DO, JR were involved in protocol design. RAA, AJF were involved in drafting protocol. GW, HS, YAO, IB, SR, DO, $J R$ were involved in critical revision of draft protocol and RAA, GW, HS, YAO, IB, SR, AJF, DO, JR were involved in approval of the final protocol.

Funding DPO is supported in part by the Gillian Reny Stepping Strong Fund. Competing interests None declared.

Ethics approval In line with guidance issued jointly by INVOLVE and the National Research Ethics Service (NRES), ethical approval is not needed for systematic reviews, even ones which involve patients and members of the public in a planning and advisory capacity.

Provenance and peer review Not commissioned; externally peer reviewed.

Data sharing statement Data will be available after the review is complete.

Open Access This is an Open Access article distributed in accordance with the Creative Commons Attribution Non Commercial (CC BY-NC 4.0) license, which permits others to distribute, remix, adapt, build upon this work noncommercially, and license their derivative works on different terms, provided the original work is properly cited and the use is non-commercial. See: http:// creativecommons.org/licenses/by-nc/4.0/

\section{REFERENCES}

1. Cancer Research UK. Breast cancer incidence statistics. Cancer Research UK, 2013 (cited 24 June 2013). http://www. cancerresearchuk.org/cancer-info/cancerstats/types/breast/ incidence/uk-breast-cancer-incidence-statistics

2. Health and Social Care Information Centre. National Mastectomy and Breast Reconstruction Audit; Fourth Annual Report. http://www. hscic.gov.uk/catalogue/PUB02731/clin-audi-supp-prog-mast-breareco-2011-rep1.pdf (accessed 28 Apr 2016).

3. Institute NC. Breast Cancer Treatment (PDQ®)-National Cancer Institute. 2013 (cited 6 September 2013). http://www.cancer.gov/ cancertopics/pdq/treatment/breast/healthprofessional

4. Le Quesne LP. David Patey's contributions to surgical oncology. Eur J Surg Oncol 1997;23:161-2.

5. Toth BA, Lappert P. Modified skin incisions for mastectomy: the need for plastic surgical input in preoperative planning. Plast Reconstr Surg 1991;87:1048-53.

6. Lanitis S, Tekkis PP, Sgourakis G, et al. Comparison of skin-sparing mastectomy versus non-skin-sparing mastectomy for breast cancer: a meta-analysis of observational studies. Ann Surg 2010;251:632-9.

7. Djohan $\mathrm{R}$, Gage $\mathrm{E}$, Gatherwright $\mathrm{J}$, et al. Patient satisfaction following nipple-sparing mastectomy and immediate breast 
reconstruction: an 8-year outcome study. Plast Reconstr Surg 2010;125:818-29.

8. Madden JL. Modified radical mastectomy. Surg Gynecol Obstet 1965;121:1221-30.

9. Hinton CP, Doyle PJ, Blamey RW, et al. Subcutaneous mastectomy for primary operable breast cancer. Br J Surg 1984;71:469-72.

10. Cense HA, Rutgers EJ, Lopes Cardozo M, et al. Nipple-sparing mastectomy in breast cancer: a viable option? Eur J Surg Oncol 2001;27:521-6.

11. Simmons RM, Brennan M, Christos $P$, et al. Analysis of nipple/ areolar involvement with mastectomy: can the areola be preserved? Ann Surg Oncol 2002;9:165-8.

12. Santoro S, Loreti A, Cavaliere F, et al. Neoadjuvant chemotherapy is not a contraindication for nipple sparing mastectomy. Breast 2015;24:661-6.

13. Veronesi U, Cascinelli N, Mariani L, et al. Twenty-year follow-up of a randomized study comparing breast-conserving surgery with radical mastectomy for early breast cancer. $N$ Engl J Med 2002;347:1227-32.

14. Wang F, Peled AW, Garwood E, et al. Total skin-sparing mastectomy and immediate breast reconstruction: an evolution of technique and assessment of outcomes. Ann Surg Oncol 2014;21:3223-30.

15. Shea BJ, Hamel C, Wells GA, et al. AMSTAR is a reliable and valid measurement tool to assess the methodological quality of systematic reviews. J Clin Epidemiol 2009;62:1013-20.

16. Shea BJ, Grimshaw JM, Wells GA, et al. Development of AMSTAR: a measurement tool to assess the methodological quality of systematic reviews. BMC Med Res Methodol 2007;7:10.

17. Shea BJ, Bouter LM, Peterson J, et al. External validation of a measurement tool to assess systematic reviews (AMSTAR). PLoS ONE 2007;2:e1350.

18. Zhang H, Li Y, Moran MS, et al. Predictive factors of nipple involvement in breast cancer: a systematic review and meta-analysis. Breast Cancer Res Treat 2015;151:239-49.
19. Piper M, Peled AW, Foster RD, et al. Total Skin-Sparing Mastectomy: A Systematic Review of Oncologic Outcomes and Postoperative Complications. Ann Plast Surg 2013;70:435-7.

20. Endara M, Chen D, Verma K, et al. Breast reconstruction following nipple-sparing mastectomy: a systematic review of the literature with pooled analysis. Plast Reconstr Surg 2013;132:1043-54.

21. De La Cruz L, Moody AM, Tappy EE, et al. Overall survival, disease-free survival, local recurrence and nipple-areolar recurrence in the setting of nipple-sparing mastectomy: A meta-analysis and systematic review. Ann Surg Oncol 2015;22:3241-9.

22. Higgins JPT, Green S, ed. Cochrane handbook for systematic reviews of interventions version 5.1.0. (updated March 2011). The Cochrane Collaboration, 2011. http://www.cochrane-handbook.org

23. Moher D, Liberati A, Tetzlaff J, et al, PRISMA Group. Preferred reporting items for systematic reviews and meta-analyses: the PRISMA statement. Int J Surg 2010;8:336-41.

24. OCEBM Levels of Evidence Working Group. The Oxford 2011 levels of evidence. Oxford Centre for Evidence-Based Medicine, 2011:5653. http://www.cebm.net/index.aspx?o=5653

25. Google. Inside Google Translate-Google Translate [Internet]. 2013. http://translate.google.com/about/intl/en_ALL/

26. Balk EM, Chung M, Chen ML, et al. Data extraction from machinetranslated versus original language randomized trial reports: a comparative study. Systemat Rev 2013;2:97.

27. Higgins JPT, Green S, ed. Table 8.5.a: The Cochrane Collaboration tool for assessing risk of bias. Cochrane handbook for systematic reviews of interventions version 5.1.0. 2011 (cited 24 June 2013). http://handbook.cochrane.org/chapter_8/table_8_5_a_the_ cochrane collaborations tool for assessing.htm

28. Sterne JAC, Higgins JPT, Reeves BC, on behalf of the development group for A-N. A Cochrane Risk Of Bias Assessment Tool: for Non-Randomized Studies of Interventions (ACROBAT-NRSI), Version 1.0.0, 24 September 2014. 2014 (cited 10 August 2015). http://www riskofbias.info

29. Sterne JAC, Sutton AJ, loannidis JPA, et al. Recommendations for examining and interpreting funnel plot asymmetry in meta-analyses of randomised controlled trials. BMJ 2011;343:d4002. 